\title{
Editorial
}

\section{Preocupaciones por la firma del CAFTA}

Cuando la presente edición de Realidad salga al público, ya se habrá consumado la firma del Tratado de Libre Comercio (TLC) entre Centroamérica y los Estados Unidos, conocido por sus siglas inglesas CAFTA. Los últimos días de diciembre de 2003 han sido testigos de la culminación de unas negociaciones controversiales, que pusieron de manifiesto la fragilidad de la integración centroamericana, subyugada al poderío de la potencia hegemónica mundial.

Antes, empero, había elementos que vaticinaban que la negociación del CAFTA terminaría en un punto muerto, sobre todo por los desencuentros alrededor del tema del agro y los productos textiles, lácteos y avícolas. Las tensiones que afloraron en los primeros intercambios entre los delegados centroamericanos y estadounidenses hacían prever cualquier cosa, menos un final armonioso. Sin embargo, la marcha contra el reloj por llegar a acuerdos en las fechas que Estados Unidos había definido desde un principio, allanó el camino. Aunque no totalmente: las nego- 
ciaciones cerraban con varios puntos pendientes de acuerdo, aunque muchos de los medios de comunicación ya anunciaban la firma de acuerdos globales.

El misterio de esa repentina conciliación de intereses puede descifrarse tomando en cuenta el poder disuasor de los delegados comerciales de la administración Bush, comenzando por el responsable de su comercio exterior, Robert Zoellick, quienes han recurrido a algo más efectivo que la llamada «diplomacia del garrote» cuando las objeciones de sus pequeñas contrapartes centroamericanas se han pasado de la raya: la amenaza de excluir a sus economías del CAFTA, el cual se ha vendido como el mejor negocio en el que se pudieron haber metido los países del Istmo.

Como telón de fondo a estos acuerdos acelerados (recuérdese que la expresión fast track, usada por Bush con el asentimiento de muchos mandatarios amigos suyos, significa literalmente "carril rápido» y sintetiza el anhelo norteamericano en las negociaciones de TLC: negociaciones expeditas, sin detenerse a cosas «menores» como derechos laborales, medio ambiente, u otras), se dieron protestas en varias ciudades centroamericanas.

En El Salvador, las manifestaciones contra la firma del TLC

El cierre de la última ronda del CAFTA conserva el mismo tono que ha caracterizado a las negociaciones del tratado comercial: en primer lugar, acuerdos globales apresurados, esto es, sin tratar a fondo los puntos sensibles para cada uno de los países centroamericanos. Esto lleva a la segunda característica: la imposibilidad por parte de las contrapartes del Istmo de llevar una posición conjunta sobre esos temas que afectan mayormente a sus productores (la lista es larga: avícolas, lácteos, textiles...), provoca que, al final, cada país negocie por separado. El lema imperial romano de «divide y vencerás» jamás tuvo tanta validez como en el desarrollo de las negociaciones del CAFTA. Si no, hay que recordar posiciones como la de Guatemala, que puso en 
aprietos al resto de los países centroamericanos al ofrecerle apertura total a los Estados Unidos.

Como prueba de esta falta de unidad, basta una muestra. Al cierre de las negociaciones, Costa Rica se había quedado rezagado de la "vía rápida» por la que han optado los demás gobiernos del Istmo. La razón reside en la firme defensa que Costa Rica ha hecho de rubros estratégicos como las telecomunicaciones, la generación de energía eléctrica y la agricultura. Costa Rica ha sido el país que ha sido más cauteloso durante todo el proceso de negociaciones del CAFTA. Se ha distinguido por su conciencia en que si bien la apertura comercial es necesaria, no puede hipotecarse el futuro de los países sometiendo a negociación aquellos rubros que están directamente ligados a la seguridad alimentaria y a la soberanía nacional.

Algunos sectores, como el avícola, han expresado su complacencia con los resultados de las negociaciones. Este sector logró un acuerdo que los beneficia con una protección durante diez años. Esta protección significa que no se reducirán aranceles hacia productos de fuera del área durante una década. Sin embargo, esta supuesta ventaja es limitada: Centroamérica no podrá exportar productos avícolas a los EEUU mientras no se halla adecuado a los estándares de aquel país.

La cantidad de puntos sensibles pendientes de negociar, la falta de respuestas concretas hacia el impacto social y económico del CAFTA, hacen que el recelo hacia el proyecto que a partir de ahora cambiará muchas cosas de las economías centroamericanas, sea inevitable.

\section{Para reflexionar: las enseñanzas del II Informe de Desarrollo Humano del PNUD}

El segundo informe sobre desarrollo humano en Centroamérica y Panamá, presentado en septiembre por el Programa de las Naciones Unidas para el Desarrollo (PNUD), sostiene que el primer quinquenio de la década de los noventa im- 
plicó transformaciones importantes en los países del Istmo. Atrás quedaban las dictaduras militares y su secuela de violaciones a los derechos humanos. También los conflictos militares tocaban a su fin y se daba paso a sistemas partidarios que, en muchos casos, incluían a actores tradicionalmente proscritos.

¿Qué ocurre a partir del segundo quinquenio de la década anterior? Ocurre que la región "ha perdido dinamismo en el ritmo de progreso que caracterizó su desarrollo humano». La recuperada estabilidad social de la región no se tradujo en la superación de aquellos indicadores que demuestran que el nivel de vida de las mayorías populares aún dista de ser decoroso.

Podría decirse, pues, que la recién instaurada democracia política en la mayoría de países centroamericanos - con todo y sus insuficiencias, como ya habremos de ver- no se tradujo automáticamente en democracia económica ni en democracia social, o dicho de otra manera, el desmontaje de los conflictos armados y de las dictaduras militares, no fue, por sí solo - ni podía serlo-, un factor que abriera mayores posibilidades de desarrollo humano para la población -i.e., acceso a empleos, educación y salud-.

Como ya es de suponerse, la excepción es Costa Rica. Otra excepción la conforma Panamá, la cual tuvo una dinámica política distinta en la década de 1980, no sin ser ajena, por ello, a las dinámicas políticas de la región. Los indicadores de desarrollo humano de este último país también están en una situación de ventaja con relación a los del resto del Istmo, están dentro (Costa Rica), o por lo menos muy cerca (Panamá) de los estándares de vida correspondientes a los de los países con alto desarrollo humano.

En lo tocante al resto de naciones, éstos se encuentran en una posición intermedia, entre los países de alto nivel de desarrollo humano y aquellos cuyo nivel es bajo.

El documento aporta un concepto a través del cual busca entender la interacción de factores que inciden en el desarrollo 
humano: en él se habla de "estilo de desarrollo», en vez de «modelo de desarrollo». Por estilo de desarrollo, «se entienden los componentes principales de una economía, y sus modalidades características de interrelación, mediante los cuales ésta enfrenta, durante una época, sus desafíos de crecimiento y desarrollo». El concepto «modelo», se explica, implicaría «una intención común" que dotaría de una "coherencia general" a las acciones y políticas de desarrollo.

De la lectura del II Informe de Desarrollo Humano, puede colegirse que el estilo de desarrollo imperante en Centroamérica, al menos en los últimos años, ha realizado un viraje importante, al abandonar la agenda de crecimiento sostenible de la región, por otra, cuyo principal componente es el libre comercio. Como lo dice el texto, la búsqueda de una agenda común se abandonó, cuando cada país se vio librado a sus propios esfuerzos para superar «los efectos del huracán Mitch y para superar conflictos bilaterales».

Como resultado de este viraje, los proyectos de integración regional se ponen en función de la perspectiva de concretar un acuerdo de libre comercio con Estados Unidos, en desmedro de otros problemas urgentes. En ese sentido, como bien se afirma en el documento, «hoy más que nunca la apertura y la negociación comercial se han constituido en los elementos que no sólo determinarán la inserción mundial de Centroamérica, sino que redefinirán la agenda de las próximas décadas».

No hay recetas preestablecidas para «salvar» al Istmo. Lo que está en el horizonte es la necesidad de buscar otro estilo de desarrollo. El actual resulta inviable: los desequilibrios que genera hacen precarios aquellos avances que puedan darse en algunos indicadores de desarrollo humano. El Informe señala que el Istmo tiene una reserva importante de personas en edad productiva, que perfectamente pueden aumentar el nivel de desarrollo económico. Sin embargo, al no haber posibilidades de acceso a educación, salud y empleo, esta reserva se torna en un problema. 
Las relaciones simplistas entre cobertura educativa y acceso al empleo demuestran sus obvias limitaciones.

El estilo de desarrollo que se busca, deberá orientarse a mejorar los estándares de vida de las mayorías. Es quimérico esperar que el «rebalse» le dé mejor salud a los que la necesitan. Es necesario replantearse el papel del Estado. Pero esto no puede ser la empresa de un solo país. Nuestras naciones son tan pequeñas y sus caminos están históricamente entrecruzados, que la búsqueda de este nuevo estilo de desarrollo, orientado al desarrollo humano, impone retomar los desafíos comunes. ¿Será posible en esta nueva etapa que abre el CAFTA o habremos perdido el rumbo para siempre? 